\title{
Editorial: State of the art research into Cognitive Load Theory
}

Citation for published version (APA):

Van Gog, T., \& Ayres, P. (2009). Editorial: State of the art research into Cognitive Load Theory. Computers in Human Behavior, 25(2), 253-257. https://doi.org/10.1016/j.chb.2008.12.007

DOI:

10.1016/j.chb.2008.12.007

Document status and date:

Published: 01/03/2009

Document Version:

Early version, also known as pre-print

Please check the document version of this publication:

- A submitted manuscript is the version of the article upon submission and before peer-review. There can be important differences between the submitted version and the official published version of record. People interested in the research are advised to contact the author for the final version of the publication, or visit the DOI to the publisher's website.

- The final author version and the galley proof are versions of the publication after peer review.

- The final published version features the final layout of the paper including the volume, issue and page numbers.

Link to publication

\section{General rights}

Copyright and moral rights for the publications made accessible in the public portal are retained by the authors and/or other copyright owners and it is a condition of accessing publications that users recognise and abide by the legal requirements associated with these rights.

- Users may download and print one copy of any publication from the public portal for the purpose of private study or research.

- You may not further distribute the material or use it for any profit-making activity or commercial gain

- You may freely distribute the URL identifying the publication in the public portal.

If the publication is distributed under the terms of Article 25fa of the Dutch Copyright Act, indicated by the "Taverne" license above, please follow below link for the End User Agreement:

https://www.ou.nl/taverne-agreement

Take down policy

If you believe that this document breaches copyright please contact us at:

pure-support@ou.nl

providing details and we will investigate your claim.

Downloaded from https://research.ou.nl/ on date: 26 Apr. 2023 
Running head: EDITORIAL

This is a pre-print of:

Ayres, P., \& Van Gog, T. (2009). Editorial: State of the art research into Cognitive Load Theory. Computers in Human Behavior, 25, 253-257.

Copyright Elsevier, available online at: http://www.elsevier.com/wps/find/journaldescription.cws_home/759/description\#description

\section{Editorial:}

State of the Art Research into Cognitive Load Theory

$$
\text { Paul Ayres }{ }^{\mathrm{a}} \text { and Tamara van Gog }{ }^{\mathrm{b}}
$$

${ }^{a}$ School of Education, University of New South Wales, Australia

${ }^{\mathrm{b}}$ Educational Technology Expertise Center, Open University of the Netherlands

Author Note

Correspondence concerning this article should be addressed to Paul Ayres, School of Education, University of New South Wales, Sydney, NSW, 2052, Australia. E-mail:

\section{p.ayres@unsw.edu.au}

Acknowledgements. The guest editors would like to thank Mireille Betrancourt, Fang Chen, Graham Cooper, Gijsbert Erkens, Eric Jamet, Tristan Johnson, Slava Kalyuga, Jim Kehoe, Liesbeth Kester, Ken Koedinger, Detlev Leutner, Fred Paas, Jan Plass, Alexander Renkl, Jean- François Rouet, Katharina Scheiter, Neil Schwartz, Rolf Schwonke, Tina Seufert, John Sweller, Huib Tabbers, Sigmar Tergan, André Tricot, Jeroen van Merriënboer, and Joachim Wirth, who acted as reviewers on this special issue. 
Editorial: State of the Art Research into Cognitive Load Theory

This special issue contains a selected set of 15 papers that were based on presentations made during the First International Conference on Cognitive Load Theory, at the University of New South Wales (Sydney, Australia) in 2007. The contributions presented here cover a variety of areas, and together provide a good overview of new research on established topics, as well as some interesting innovative directions inspired by Cognitive Load Theory (CLT: Sweller, 1988; Sweller, Van Merriënboer, \& Paas, 1998; Van Merriënboer \& Sweller, 2005). Together, the papers comprise seven themes: learning from worked examples; learning by adding diagrams to text; self-regulation and learner control; group learning; measuring cognitive load and cognitive processes; learning from dynamic visualizations; and, learning in hypermedia environments and the impact of prior knowledge. Whereas most papers have a clear research focus within a single theme, some have additional findings that are relevant to other themes. The papers have been organized into two main sections. The first is entitled Instructional designs for the development of transferable knowledge and skills and contains the manuscripts focusing on worked examples, self-regulation and learner control, group learning, and cognitive load measurement. The second section is called Learning from dynamic visualizations and hypermedia environments and contains the studies on animations and hypermedia. Each section is followed by a discussion.

This editorial starts by describing some of the basic principles of CLT; we then describe the themes and briefly introduce the individual papers and discussion papers within those themes.

\section{Cognitive Load Theory}

For over a quarter of century now, research inspired by CLT has contributed significantly towards effective instructional designs, based on our understanding of the cognitive architecture, and its engagement during learning episodes and problem solving. It 
has developed from a theory in its early beginnings that focused on problem solving (see Sweller, 1988) to a more recent re -conceptualization as a learning theory with an evolutionary biological base (see Sweller, 2004; Sweller \& Sweller, 2006). CLT has identified a number of effects, such as the worked example, goal-free, split-attention, redundancy, modality, expertise reversal and imagination effect (for reviews see Sweller et al., 1998; Van Merriënboer \& Ayres, 2005; Van Merriënboer \& Sweller, 2005), that have led to enhanced instructional design guidelines and thereby to more effective learning environments.

At the centre of CLT is the human memory system, in particular the relations between working and long-term memory. CLT is based on a model of human cognitive architecture that assumes that working memory (WM) is very limited in terms of being able to store and process information (Cowan, 2001; Miller, 1956); whereas long term memory (LTM) has a vast capacity, able to store an almost limitless amount of information. Essential to the development of expertise and problem solving capabilities is the construction of schemas in LTM, that is, knowledge structures organized around central concepts. In the construction of those schemata, however, the WM limitations in capacity and duration are a bottleneck, as this is where information elements need to be processed, combined, rehearsed, etc. before they can become consolidated in LTM. These limitations become especially pronounced when dealing with complex tasks that are high in intrinsic cognitive load, that is, tasks containing a high number of novel, interacting information elements.

As expertise develops, schemas are formed and elaborated, that is, they become more complex and connect together many linked areas of knowledge. As well as providing the foundation of our knowledge base, schemas also enable us to overcome the capacity limitations of WM. Schematic information brought into WM represents only a single element of information. As a consequence, intrinsic load is lower and more capacity is available in 
WM to store and process new information. Furthermore, if schemas are automated, they can be recalled and executed rather effortlessly in WM, further reducing the burden on WM. In common with many other theories of learning, CLT recognises the importance of prior knowledge to support further learning. However, this not just from a motivational or cultural perspective, but in recognition that the limited capacity of WM can be a major impediment to learning. All conscious learning takes place in WM, therefore using prior knowledge in the form of schemas enables us to not only make sense of new information, but also reduces the likelihood of WM becoming overloaded and leading to a breakdown in learning.

Because CLT research has emphasized the importance of WM, much of the research has focused on identifying instructional designs that create unnecessary WM load, and providing more effective or efficient alternatives. Problem solving strategies, redundancy and splitattention effects are all examples of designs that increase extraneous cognitive load, that is, cognitive load caused by the instructional design that is ineffective for learning. Worked examples, non-redundant materials, and integrated materials, were therefore found to be more effective for learning, respectively (see Sweller et al., 1998). In addition, when information to be learned is too complex, that is, when intrinsic load is too high, this load can be decreased by temporarily reducing the number of elements that need to be processed in WM at the same time (see Ayres, 2006; Pollock, Chandler \& Sweller, 2002). Both the previously described situations are concerned with reducing cognitive load (both intrinsic and extraneous), which is highly desirable in those cases, as learning would otherwise be hampered. Nevertheless, this type of research has for a long time dominated CLT research, and has led to the misconception that CLT propagates reduction of cognitive load and effortless learning in general. This is not true, as CLT also emphasizes that an equally important consideration is to ensure that learning (schema acquisition) is optimized. For learning to occur, learners must actively engage in processes that impose a germane cognitive load, which is facilitated by the 
instructional design but is effective for learning (i.e., schema construction). Researchers have identified a number of strategies to increase germane load, mostly in relation to worked examples (see Paas \& Van Gog, 2006), such as increasing variability in sequences of worked examples (e.g., Paas \& Van Merriënboer, 1994) or prompting self-explanations during worked examples study (e.g., Atkinson \& Renkl, 2007).

In summary, CLT argues that there are three vital aspects to designing effective learning environments. Two focus on reducing working memory load: that caused by poorly designed instructional materials, and if necessary (when tasks/materials are too complex) that caused by the materials to be learned themselves. The third is concerned with optimizing WM load, for processes related to learning. As mentioned before, much of the research into CLT has been concerned with reducing extraneous load and to a lesser extent intrinsic load. The state of the art research shown in this special issue indicates a much greater focus on the third vital aspect: optimizing germane cognitive load.

Contributions in the Special Issue

Section 1: Instructional Designs for the Development of Transferable Knowledge and Skills Learning from Worked Examples

The topic of learning from worked out examples has a long tradition in cognitive load research (Cooper \& Sweller, 1987; Sweller \& Cooper, 1985; see also Paas \& Van Gog, 2006). Research has consistently shown that for novices, instruction consisting of studying worked examples is more effective and efficient than instruction consisting of solving the equivalent problems (for overviews see e.g., Atkinson, Derry, Renkl, \& Wortham, 2000; Renkl, 2005; Sweller et al., 1998). This became known as the worked example effect. The study by Schwonke, Renkl, Krieg, Wittwer, Aleven, and Salden (this issue) provides an important addition to the worked examples literature. It addresses the arguments by some critics of the worked example effect that it is mainly due to 'lousy' control conditions, that is, it is superior 
to problem solving without any instructional guidance at all, but would it also be superior to forms of guided instruction? Schwonke et al. compare the effectiveness of worked examples presented in a fading strategy with problem solving, both supported by an intelligent tutor that provided feedback and scaffolding. Their results lend further support to the robustness of the worked example effect for developing both procedural and conceptual understanding. This study also demonstrates how the two instructional approaches (faded worked examples and intelligent tutors) can be successfully combined.

Hilbert and Renkl (this issue) also extend the research into worked examples by focusing on examples not as a means to teach domain content knowledge as is usually the case, but to teach a heuristic strategy for learning in the form of computer-based concept mappings. In this study learners who studied heuristic examples on concept mapping were compared with learners who practiced concept mapping. Their results show that heuristic examples were only effective when combined with self-explanation prompts.

Although not primarily about example-based learning, Van Gog, Kester, Nievelstein, Giesbers, and Paas (this issue), discuss how techniques that can be used to uncover cognitive processes, like concept mapping, verbal reporting, or eye tracking, can also be applied directly in examples. That is, examples may not only be thought of as consisting of a worked-out solution, but also as a model demonstrating a solution. In this case, hearing the model verbalize his/her thought processes, or being able to observe the model's allocation of attention through his/her eye movements, may focus learners' attention more on the relevant strategies or task aspects, thereby increasing their understanding of presented solution procedures.

\section{Learning by Adding Diagrams to Text}

Researchers have known for a long time that diagrams can be a very effective aid to learning either by themselves or in conjunction with a written or spoken text (see Marcus, 
Cooper \& Sweller, 1996; Mayer \& Moreno, 2003; Schnotz, 2005). However, the multimedia approach of combining diagrams with text can be detrimental if unintentional extraneous cognitive load is created; by either positioning the text away from the diagram (the splitattention effect, see Ayres \& Sweller, 2005; Chandler \& Sweller, 1991) or repeating the same information in both sources (the redundancy effect, see Chandler \& Sweller, 1991; Sweller, 2005). The following two papers add to this literature on text and diagrams.

Kehoe et al. (this issue) investigated the impact of adding illustrations to text in learning about computer applications (word processing and internet usage) with adult novices. Both positive and negative effects of illustrations were found, depending on what type of tasks was set. Illustrations aided learning in following the textual instructions but were less helpful in remembering whole procedures. Redundancy effects were observed, but significantly a metacognitive engagement led to a deeper processing of the training material.

Leutner, Leopold, and Sumfleth (this issue) investigate the effectiveness of visualizations generated by the learners themselves while reading science text. They found that whereas an instruction to mentally visualize while reading seemed to increase comprehension and lower cognitive load, the requirement to draw these visualizations had the reverse effect, reducing comprehension and increasing cognitive load.

\section{Self-regulation and Learner Control}

An emerging topic in CLT, which is getting more attention, is self-regulation and the role of motivational and affective factors in learning. Research suggests that providing novice learners with full control over which learning tasks to work on, imposes too high an extraneous load, even though it seems to enhance learners' motivation or involvement (see e.g., Corbalan, Kester, \& Van Merriënboer, in press; Scheiter \& Gerjets, 2007). Therefore, an important question is how learner control could be provided without overloading the learner. Corbalan et al. (in press) opted for shared control over task selection (i.e., a set of tasks is pre- 
selected by the environment, from which the learner chooses the one she or he wants to work on), which they indeed found to be a good way to maintain positive effects on involvement without detrimental effects on learning. The study presented here by Corbalan, Kester, and Van Merriënboer (this issue) extends these findings by showing that shared control is only effective when learners have the feeling they actually have something to choose. That is, if the tasks among which they could choose were all highly similar to the previous task, shared control did not have positive effects.

The Wirth, Künsting, and Leutner (this issue) study investigated the goal-specificity effect (goal vs. goal-free, see Ayres, 1993; Sweller, Mawer \& Ward, 1983) from both a problem solving and a learning goal perspective. Results found that within a problem solving framework the goal-free condition led to both better performance and reduced cognitive load than a goal specific condition, but within a learning framework led only to reduced cognitive load without a corresponding difference in performance. It was also found that the goal-free approach and the learning framework were more likely to elicit a learning strategy than a goal specific or problem-solving approach. This study has important implications for cognitive load research on self-regulated learning. Different learners are likely to have different goals which mediate their learning strategies and as a consequence their cognitive load and learning outcomes (see also Gerjets \& Scheiter, 2003).

The study by Leutner et al. (this issue; see description above) also can be regarded from the perspective of self-regulated learning. When learners read plain text they may use particular visualization strategies to compensate for a lack of diagrams, either by forming an internal mental image or by drawing an external representation on paper.

\section{Group Learning}

The article by Kirschner, Paas, and Kirschner (this issue), moves in an important and highly innovative new direction for CLT research, by addressing the question of whether on 
complex tasks, group learning becomes more effective because more processing capacity is available. Kirschner et al., hypothesized that a collaborative group can cope more easily with the limited working memory capacity of individuals by creating a combined group working memory with greater capacity, and therefore enabling more learning to occur from complex tasks. In support of this argument they found that retention was higher for participants who had worked individually, but transfer (i.e., new, flexible applications of what was learned) was higher for participants who had worked in groups, suggesting that group members can invest more cognitive resources in processes that directly contribute to high-quality and flexible schema development. In the discussion, they also raise a number of interesting questions for further research on how current cognitive load principles may or may not apply to group learning situations.

\section{Measuring Cognitive Load and Cognitive Processes}

A more general issue that pertains to many of the studies presented here concerns the measurement of cognitive load. The researchers in this special issue use a variety of measures and combinations of measures to assess it. Measurement of cognitive load has been a very important tool in the development of CLT. In the early stages researchers mainly used indirect methods such as time to solution and error rates, as well as some limited uses of a dual-task methodology (see Sweller, 1988). However, a significant breakthrough occurred when Paas (1992) introduced a subjective measure. This global measure of cognitive load requires learners to rate (perceive) the amount of mental effort invested during learning and testing phases, and has been used extensively in CLT for more than 15 years. However, in more recent times, researchers have wanted to gain a deeper understanding of the cognitive processes evoked during learning episodes and have thus required more information about the influence of different types of cognitive load. 
Representing a move away from the global measure, Cierniak, Scheiter and Gerjets (this issue) proposed a set of separate subjective scale items to measure intrinsic, extraneous, and germane load individually. In this study, which also used a dual-task methodology, the split-attention effect (a split source format was compared with an integrated format, see Ayres \& Sweller, 2005) was investigated in a physiological learning domain. The dual-task findings suggested that overall cognitive load was the same for both groups; however, results obtained with the subjective rating scales suggested that the split attention effect was mediated by both extraneous load and intrinsic cognitive load, according to the individual measures. This finding is in line with the general goal of CLT, in that the superior learning format (integrated text and diagrams) reduced extraneous load and promoted germane load.

Van Gog et al. (this issue) emphasize that it is also important for CLT researchers to try and capture the processes that impose certain kinds and/or amounts of load more directly, in order to increase our understanding of why certain effects occur or fail to occur. They discuss how techniques such as concept mapping, verbal reporting, or eye tracking, can be used as a means to uncover such information, and in addition, can be used to assess acquired cognitive structures (i.e., learning outcomes) at a more detailed level than our performance measures usually do. These techniques should not replace others, but could be an informative addition to other techniques. Combinations of different kinds of cognitive load measures or measurement techniques can provide better insight into the quality of acquired cognitive structures. For example, the efficiency measure originally proposed by Paas and Van Merriënboer (1993; see also Kirschner et al., this issue), relies on a combination of test performance and mental effort invested in the test, to assess the quality of learning outcomes. In the past, it has also been adapted in more economic terms, as the relation between test performance and effort invested in the study phase to attain that performance (see Van Gog \& Paas, 2008, for an overview). Gerjets, Scheiter, Opfermann, Hesse, and Eysink (this issue) 
make another adaptation using time invested in the study phase, which is also a more economic definition of efficiency. It is important to note though, that the different measures of cognitive load and efficiency assess different constructs and as a consequence, have different implications for the conclusions that can be drawn from the studies (see Van Gog \& Paas, 2008).

Finally, a very unique challenge for cognitive load measurement is presented by the Kirschner et al. (this issue) paper: How do we conceptualize and measure "group cognitive load"?

\section{Discussion of Section 1}

The discussion of the papers in this section is provided by Slava Kalyuga (this issue). He analyzes these papers in terms of issues related to the acquisition of deep, transferable knowledge structures and the development of metacognitive and self-regulation skills.

\section{Section 2: Learning from Dynamic Visualizations and Hypermedia Environments}

Another topic that has been studied for quite a while in cognitive load research, but continues to result in seemingly contradictory findings, is the effectiveness of static versus dynamic visualizations (see also Ayres \& Paas, 2007a,b). In their review of the literature, Tversky, Morrison, \& Betrancourt (2002) showed that although dynamic visualizations seem an intuitively superior instructional format for representing change over time than static graphics, the superiority of dynamic over static visualizations could not always be demonstrated empirically. In a recent meta-analysis, Höffler and Leutner (2007) came to the more positive conclusion that dynamic visualizations were more effective than static visualizations under certain conditions. In particular, the effect was greater when the animation was representational (as opposed to decorational), when it was highly realistic, and when procedural-motor knowledge was to be acquired.

The procedural-motor condition is consistent with a potential explanation based on 
neuroscience research recently provided by Van Gog, Paas, Marcus, Ayres, and Sweller (2008). They argued that the mirror-neuron system, which is activated when we perform a movement ourselves, but also when we observe someone performing a movement, might explain why dynamic visualizations are often effective for tasks containing human movement, but not for content demonstrating other kinds of movement. The studies presented here by Wong et al. (this issue) and Ayres, Marcus, Chan, and Qian (this issue) investigate this possibility. In both studies human movement tasks were devised that involved hand manipulations in the form of origami tasks (Wong et al.), or knot tying and puzzle rings (Ayres et al.). The two sets of results are in line with the findings by Höffler and Leutner and lend some support to the assumption by Van Gog et al., as they consistently show that dynamic visualizations can be superior to static visualizations on tasks involving human movement. An interesting issue raised by the (combination of the) Wong et al. and Ayres et al. studies, is that concerning cognitive representations of the motor task and transfer from the motor task to related cognitive tasks (e.g., inferring previous or next steps). It seems that such transfer may depend on the complexity of the material, at least when the number of static frames required to convey the content in the static conditions can be taken as an indicator of complexity.

Furthermore, Arguel and Jamet (this issue) found that for their task which also involved observational learning of procedural motor knowledge in a very real-world learning domain (first aid procedures), a combination of dynamic and static visualizations, was more effective than either format alone. However, they found in a second experiment that this was only the case when the number of static visualizations presented was low, with higher numbers the effect disappeared, probably due to a redundancy effect (see Chandler \& Sweller, 1991). The approach by Arguel and Jamet in combining statics with animations is quite unusual, as much of the research in this field has compared statics with animations, a notable 
exception being a study by Paas, Van Gerven and Wouters (2007) that followed an animated instructional episode with a sequence of key static frames from the animation. A further feature of the Arguel and Jamet paper was the finding that the best strategy was to present the statics one at-a-time (dynamically) in synchronization with the animation content.

\section{Learning in Hypermedia Environments and the Impact of Prior Knowledge}

One of the learner characteristics that is frequently investigated in CLT, and is known to substantially affect the effectiveness of instructional formats, is the learner's level of prior knowledge. Research on what has become known as "the expertise reversal effect" (for an overview see Kalyuga, Ayres, Chandler, \& Sweller, 2003) has shown that instructional formats that have positive effects on novices' learning outcomes, may have detrimental effects on learning when learners have a high degree of prior knowledge, and vice versa. The studies by Gerjets et al. (this issue) Schnotz and Heiß (this issue), and Amadieu, Tricot, and Mariné (this issue), extend the research on prior knowledge to learning in hypermedia environments, in which the learner has a high degree of control over what to study, when to study it, and for how long.

Amadieu et al. (this issue) investigated the impact of prior knowledge on learning from either a hierarchical structure (organisational links) or a network structure (relational links). Results indicated that low prior knowledge learners benefited from the hierarchical structure but high prior knowledge learners from the network structure. An interesting aspect of this study was that the amount of disorientation caused by the hypermedia environment was also measured as well as cognitive load. Schnotz and Heiß (this issue) investigated how semantic scaffolds should be best presented in a hypermedia environment. Results indicated that high prior knowledge learners benefited from the use of semantic scaffolds, but low prior knowledge learners did not. In addition, learners with low prior knowledge performed better with an optional presentation, whereas high prior knowledge performed better with an 
obligatory presentation, which allowed the removal of the scaffolds. Overall learners generally preferred the optional presentation of learning scaffolds even though it did not benefit all learners. Gerjets et al. (this issue) investigated whether general multimedia design principles, such as the split-attention and modality principles, can be applied to hypermedia learning environments, and to what extent the impact of learner control was dependent upon prior knowledge. Results indicated that there was little evidence to support the assumption that multimedia principles can be implemented in a hypermedia environment. It was also found that a high level of learner control had a positive influence on learning outcomes, irrespective of the learner's prior knowledge.

\section{Discussion of Section 2}

The papers in this section are discussed by Paul Chandler (this issue), who also comments more broadly on the impact of dynamic visualisations and hypermedia on learning environments. 


\section{References}

Amadieu, F., Tricot, A., \& Mariné, C. (this issue). Prior knowledge in learning from a nonlinear electronic document: Disorientation and coherence of the reading sequences. Computers in Human Behavior, $x x, \mathrm{xxx}-\mathrm{xxx}$.

Arguel, A., \& Jamet, E. (this issue). Using video and static pictures to improve learning of procedural contents. Computers in Human Behavior, $x x$, $\mathrm{xxx}-\mathrm{xxx}$.

Atkinson, R. K., Derry, S. J., Renk1, A., \& Wortham, D. (2000). Learning from examples: Instructional principles from the worked examples research. Review of Educational Research, 70, 181-214.

Atkinson, R. K., \& Renkl, A., (2007). Interactive example-based learning environments: Using interactive elements to encourage effective processing of worked examples. Educational Psychology Review, 19, 375-386.

Ayres, P. (1993). Why Goal-free problems can facilitate learning. Contemporary Educational Psychology, 18, 376-381.

Ayres, P. (2006). Using subjective measures to detect variations of intrinsic cognitive load within problems. Learning and Instruction, 16, 389-400.

Ayres, P., Marcus, N., Chan, C., \& Qian, N. (this issue). Learning hand manipulative tasks: When instructional animations are superior to equivalent static representations. Computers in Human Behavior, $x x, \mathrm{xxx}-\mathrm{xxx}$.

Ayres, P., \& Paas, F. (2007a). Making instructional animations more effective: A cognitive load approach. Applied Cognitive Psychology, 21, 695-700.

Ayres, P., \& Paas, F. (2007b). Can the cognitive load approach make instructional animations more effective? Applied Cognitive Psychology, 21, 811-820. 
Ayres, P., \& Sweller, J. (2005). The split-attention principle in multimedia learning. In R.E. Mayer (Ed.), The Cambridge Handbook of Multimedia Learning (pp. 135-146). New York: Cambridge University Press.

Chandler, P. (this issue). Dynamic visualisations and hypermedia: Beyond the "wow" factor. Computers in Human Behavior, xx, $\mathrm{xxx}-\mathrm{xxx}$.

Chandler, P., \& Sweller, J. (1991). Cognitive load theory and the format of instruction. Cognition and Instruction, 8, 293-332.

Cierniak, G., Scheiter, K., \& Gerjets, P. (this issue). Explaining the split-attention effect: Is the reduction of extraneous cognitive load accompanied by an increase in germane cognitive load? Computers in Human Behavior, xx, $\mathrm{xxx}-\mathrm{xxx}$.

Cooper, G., \& Sweller, J. (1987). The effects of schema acquisition and rule automation on mathematical problem-solving transfer. Journal of Educational Psychology, 79, 347362.

Corbalan, G., Kester, L., \& Van Merriënboer, J. J. G. (in press). Selecting learning tasks: Effects of adaptation and shared control on efficiency and task involvement. Contemporary Educational Psychology.

Corbalan, G., Kester, L., \& Van Merriënboer, J. J. G. (this issue). Combining shared control with variability over surface features: Effects on transfer test performance and task involvement. Computers in Human Behavior, $x x$, xxx-xxx.

Cowan, N. (2001). The magical number 4 in short-term memory: A reconsideration of mental storage capacity. Behavioral \& Brain Sciences, 24, 87-114.

Gerjets, P., \& Scheiter, K. (2003). Goal configurations and processing strategies as moderators between instructional design and cognitive load: Evidence from hypertextbased instruction. Educational Psychologist, 38, 33-41. 
Gerjets, P., Scheiter, K., Opfermann, M., Hesse, F. W., \& Eysink, T. H. S. (this issue). Learning with hypermedia: The influence of representational formats and different levels of learner control on performance and learning behaviour. Computers in Human Behavior, $x x, \mathrm{xxx}-\mathrm{xxx}$.

Hilbert, T., \& Renk1, A. (this issue). Learning how to use a computer-based concept-mapping tool: Self-explaining examples helps. Computers in Human Behavior, $x x$, $\mathrm{xxx}-\mathrm{xxx}$.

Höffler, T. N., \& Leutner, D. (2007). Instructional animation versus static pictures: A metaanalysis. Learning and Instruction, 17, 722-738.

Kalyuga, S. (this issue). Instructional design for the development of transferable knowledge and skills: A cognitive load perspective. Computers in Human Behavior, xx, $\mathrm{xxx}-\mathrm{xxx}$.

Kalyuga, S., Ayres, P., Chandler, P., \& Sweller, J. (2003). The expertise reversal effect. Educational Psychologist, 38, 23-31.

Kehoe, E. J., Bednall, T., Yin, L., Olsen, K. N., Pitts, C., Henry, J. D., \& P. E. Bailey (this issue). Training adult novices to use computers: Effects of different types of illustrations. Computers in Human Behavior, $x x$, $\mathrm{xxx}-\mathrm{xxx}$.

Kirschner, F., Paas, F., \& Kirschner, P. (this issue). Individual and group-based learning from complex cognitive tasks: Effects on retention and transfer efficiency. Computers in Human Behavior, $x x$, $\mathrm{xxx}-\mathrm{xxx}$.

Leutner, D., Leopold, C., \& Sumfleth, E. (this issue). Cognitive load and science text comprehension: Effects of drawing and mentally imagining text content. Computers in Human Behavior, $x x$, $\mathrm{xxx}-\mathrm{xxx}$.

Marcus, N., Cooper, M., \& Sweller, J. (1996). Understanding instructions. Journal of Educational Psychology, 88, 49-63.

Mayer, R. E., \& Moreno, R. (2003). Nine ways to reduce cognitive load in multimedia learning. Educational Psychologist, 38, 43-52. 
Miller,G. A. (1956).The magical number seven, plus or minus two: Some limits on our capacity to process information. Psychological Review, 63, 81-97.

Paas, F. (1992). Training strategies for attaining transfer of problem-solving skill in statistics: A cognitive load approach. Journal of Educational Psychology, 84, 429-434.

Paas, F., Van Gerven, P.W.M., \& Wouters, P. (2007). Instructional efficiency of animation: Effects of interactivity through mental reconstruction of static key frames. Applied Cognitive Psychology, 21, 783-793.

Paas, F., \& Van Gog, T. (2006). Optimising worked example instruction: Different ways to increase germane cognitive load. Learning and Instruction, 16, 87-91.

Paas, F., \& Van Merriënboer, J. J. G. (1993). The efficiency of instructional conditions: An approach to combine mental effort and performance measures. Human Factors, 35, 737-743.

Paas, F., \& Van Merriënboer, J. J. G. (1994). Variability of worked examples and transfer of geometrical problem-solving skills: A cognitive-load approach. Journal of Educational Psychology, 86, 122-133.

Pollock, E., Chandler, P., \& Sweller, J. (2002) Assimilating complex information. Learning and Instruction, 12, 61-86.

Renkl, A. (2005). The worked-out examples principle in multimedia learning. In R. E. Mayer (Ed.), The Cambridge handbook of multimedia learning (pp. 229-246). New York: Cambridge University Press.

Scheiter, K., \& Gerjets, P. (2007). Learner control in hypermedia environments. Educational Psychology Review, 19, 285-307.

Schnotz, W. (2005). An integrated model of text and picture comprehension. In R.E. Mayer (Ed.), The Cambridge Handbook of Multimedia Learning (pp.49-69). New York: Cambridge University Press. 
Schnotz, W., \& Heiß, A. (this issue). Semantic scaffolds in hypermedia learning environments. Computers in Human Behavior, xx, $\mathrm{xxx}-\mathrm{xxx}$.

Schwonke, R., Renkl, A., Krieg, C., Wittwer, J., Aleven, V., \& Salden, R. (this issue). The worked-example effect: Not an artefact of lousy control conditions. Computers in Human Behavior, xx, xxx-xxx.

Sweller, J. (1988). Cognitive load during problem-solving: Effects on learning. Cognitive Science, 12, 257-285.

Sweller, J. (2004). Instructional design consequences of an analogy between evolution by natural selection and human cognitive architecture. Instructional Science, 32, 9-31.

Sweller, J. (2005). The redundancy principle in multimedia learning. In R.E. Mayer (Ed.), The Cambridge Handbook of Multimedia Learning (pp.159-167). New York: Cambridge University Press.

Sweller, J., \& Cooper, G. A. (1985). The use of worked examples as a substitute for problem solving in learning algebra. Cognition and Instruction, 2, 59-89.

Sweller, J., Mawer, R. F., \& Ward, M. R. (1983). Development of expertise in mathematical problem solving. Journal of Experimental Psychology, 112, 639-661.

Sweller, J., \& Sweller, S. (2006). Natural information processing systems. Evolutionary Psychology, 4, 434-458.

Sweller, J., Van Merriënboer, J. J. G., \& Paas, F. (1998). Cognitive architecture and instructional design. Educational Psychology Review, 10, 251-295.

Tversky, B., Morrison, J. B., \& Betrancourt, M. (2002). Animation: Can it facilitate? International Journal of Human-Computer Studies, 57, 247-262.

Van Gog, T., Kester, L., Nievelstein, F., Giesbers, B., \& Paas, F. (this issue). Uncovering cognitive processes: Different techniques that can contribute to cognitive load research and instruction. Computers in Human Behavior, $x x, \mathrm{xxx}-\mathrm{xxx}$. 
Van Gog, T., \& Paas, F. (2008). Instructional efficiency: Revisiting the original construct in educational research. Educational Psychologist, 43, 16-26.

Van Gog, T., Paas, F., Marcus, N., Ayres, P., \& Sweller, J. (2008). Instructional design consequences of the mirror-neuron system for observational learning. Manuscript submitted for publication.

Van Merriënboer, J. J. G., \& Ayres, P. (2005). Research on cognitive load theory and it's design implications for e-learning, Educational Technology Research and Development, 53(3), 5-13.

Van Merriënboer, J. J. G., \& Sweller, J. (2005). Cognitive load theory and complex learning: Recent developments and future directions. Educational Psychology Review, 17, 147177.

Wirth, J., Künsting, J., \& Leutner, D. (this issue). The impact of goal specificity and goal type on learning outcome and cognitive load. Computers in Human Behavior, xx, xxx-xxx.

Wong, A., Marcus, N., Ayres, P., Smith, L., Cooper, G. A., Paas, F., \& Sweller, J. (this issue). Instructional animations can be superior to statics when learning human motor skills. Computers in Human Behavior, $x x, \mathrm{xxx}-\mathrm{xxx}$. 